\title{
Isolated Spinal Subdural Empyema: A Case Report \& Review of the Literature
}

\author{
Rudy D. Marciano ${ }^{1,2 *}$, Ward Buster ${ }^{2}$, Chris Karas' ${ }^{1}$, Kailash Narayan ${ }^{1}$ \\ ${ }^{1}$ Department of Neurosurgery, OhioHealth, Grant Medical Center, Columbus, OH, USA \\ ${ }^{2}$ Department of Neurosurgery, OhioHealth, Riverside Methodist Hospital, Columbus, OH, USA \\ Email: ${ }^{\star}$ rudy.marciano@ohiohealth.com
}

How to cite this paper: Marciano, R.D., Buster, W., Karas, C. and Narayan, K. (2017) Isolated Spinal Subdural Empyema: A Case Report \& Review of the Literature. Open Journal of Modern Neurosurgery, 7, 112-119.

https://doi.org/10.4236/ojmn.2017.73012

Received: April 26, 2017

Accepted: July 23, 2017

Published: July 26, 2017

Copyright () 2017 by authors and Scientific Research Publishing Inc. This work is licensed under the Creative Commons Attribution International License (CC BY 4.0).

http://creativecommons.org/licenses/by/4.0/

\section{Open Access}

\begin{abstract}
Background: Spinal subdural empyema (SSE) is rare, with less than 70 case reports in adults. The pathomechanism of infection and vulnerable patient populations have yet to be delineated. Reported outcomes are varied. Case Description: Case report of an isolated spinal subdural empyema with no obvious source in a 65-year-old female presenting with an acute neurologic deficit requiring emergent surgical intervention. A Pub Med search of keywords "Spinal Subdural Empyema" and/or "Spinal Subdural Abscess" with review of all associated English language literature was conducted. Pertinent data were compiled, analyzed, and placed into chart and graph format. Conclusions: SSE is rare and often progresses in 3 separate chronologic stages; pain/fever, neurologic deficit, and paralysis. Tenderness to palpation is often absent. 3 methods of spread have been postulated: hematogenous, contiguous, and iatrogenic. Staphylococcus aureus is the most common infecting organism. The lumbar spine, followed closely by the thoracic spine, is most commonly affected. Contrasted MRI is the preferred diagnostic modality. Emergent surgical SSE evacuation followed by parenteral antibiotics is recommended, as surgical outcomes are far superior to non-surgical management. The patient featured in this case made a full neurologic recovery by 6 -month follow-up.
\end{abstract}

\section{Keywords}

Subdural Empyema, Subdural Abscess, Spinal Subdural Empyema, Epidural Abscess, Infection, Spinal Infection

\section{Introduction}

SSE is rare, with less than 70 reported cases of this pathology in adults. Due to its rarity, the suspected pathomechanisms of infection are not well understood. While populations likely to develop spinal epidural abscess (SEA) such as those 
with chronic sinus infections or conditions promoting immunosuppression, such as diabetes mellitus, systemic malignancies, use of immunosuppressive drugs, or intravenous drug abuse are likely the most at risk patient populations to also develop SSE, this has yet to be delineated given the rarity of the pathology. The reported outcomes are varied in the literature [1] [2] [3] [4].

This case outlines the presentation, diagnosis, clinical course, risk factors, and treatment of a case of Streptococcus agalactiae SSE. Existing case report data was acquired via a Pub Med search of keywords "Spinal Subdural Empyema” and/or "Spinal Subdural Abscess" with review of all associated English language literature.

\section{Case Report}

A healthy 65-year-old female presented with axial back pain, paraparesis, paresthesias, myelopathy, and a mild leukocytosis after being hospitalized with community acquired pneumonia 2 weeks prior. She underwent L3-5 laminectomy 7 months prior without a dural tear. MRI revealed a SSE from T8 to L4. The patient underwent emergent T10-L3 laminectomy with dural opening, exploration, and washout of the SSE. Intra-operative cultures grew Streptococcus agalactiae. The patient was treated with intravenous ceftriaxone and made a full recovery at 6 months post-operatively (Figures 1-3).

\section{Results}

$46 \%$ of SSE cases occurred in those between ages 50 and 69 with a slight female predilection. $53 \%$ of reported cases affected the lumbar spine, followed by $43 \%$ thoracic, 37\% cervical, and 11\% sacral. Staphylococcus aureus was cultured in $52 \%$ of cases. Methicillin resistant Staphylococcus aureus was cultured in 2 cases. All Streptococcus species were cultured in 15\% of cases. $19 \%$ of cases were reported as either sterile or unknown. 15\% of cases were listed as "Other" and consist of a variety of single cases of different organisms. $74 \%$ of patients suffered a neurologic deficit and 68\% will reported back/neck pain and/or fever. $57 \%$ of patient presented with a leukocytosis. Tenderness to palpation was
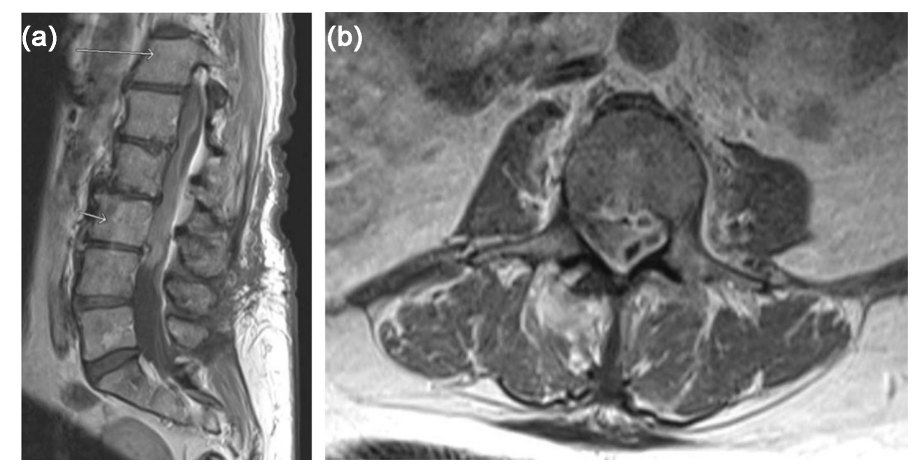

Figure 1. (a) Pre-operative sagittal T-1 weighted post-contrast MRI of the lumbar spine shows diffuse subdural collection with no evidence of epidural extension. (b) Pre-operative axial T-1 weighted post-contrast MRI of the L3 vertebral body level shows loculated subdural collection effacing the thecal sac. 


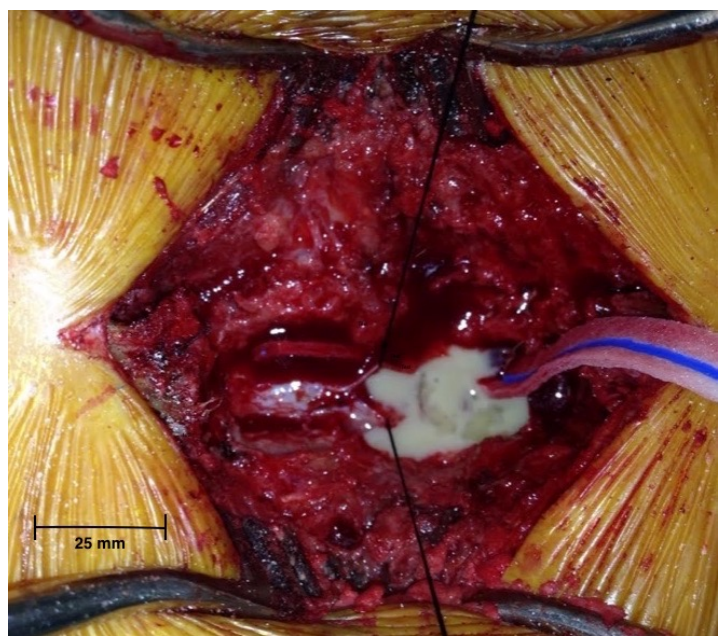

Figure 2. Intraoperative photograph shows significant purulence in the subdural space with no evidence of gross epidural infection.
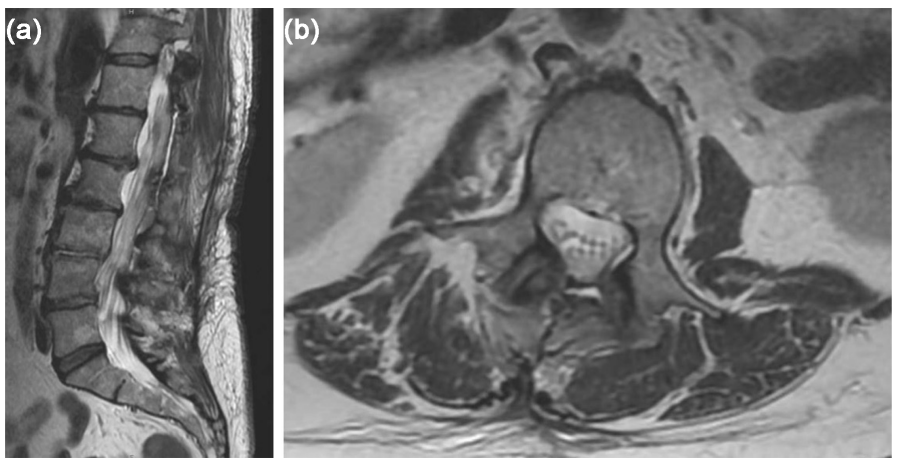

Figure 3. (a) Post-operative sagittal T-2 weighted MRI of the lumbar spine shows resolution of the diffuse subdural collection. (b) Post-operative axial T-2 weighted MRI of the L2 vertebral body level shows resolution of the subdural collection with reconstitution of the thecal sac.

present in $23 \%$ of cases. Hematogenous spread occurred in $43 \%$ of cases. $28 \%$ of cases consisted of contiguous spread. $25 \%$ of cases were iatrogenic. $43 \%$ of patients managed with antibiotics alone died and another $14 \%$ had minimal recovery. $73 \%$ of patients managed with surgical evacuation of the empyema and parenteral antibiotics had full or marked recoveries. The mortality rate of surgically treated spinal subdural empyema is $13 \%$ (Figures $4-8$ ).

\section{Discussion}

Spinal subdural empyema is rare, with less than 70 case reports on this pathology in adults [3] [5] [6]. The presentation of spinal subdural empyema has been described in 3 separate stages which often, but not always, progress in chronologic order at unpredictable rates [4] [7]. Most commonly, the presenting signs and symptoms are fever, back/neck pain, and radicular pain referred to affected nerve roots. $68 \%$ of patients will present with fever and/or back/neck pain. Next, the patients typically experience motor and sensory deficits and urinary sphincter 
18

13.5

9

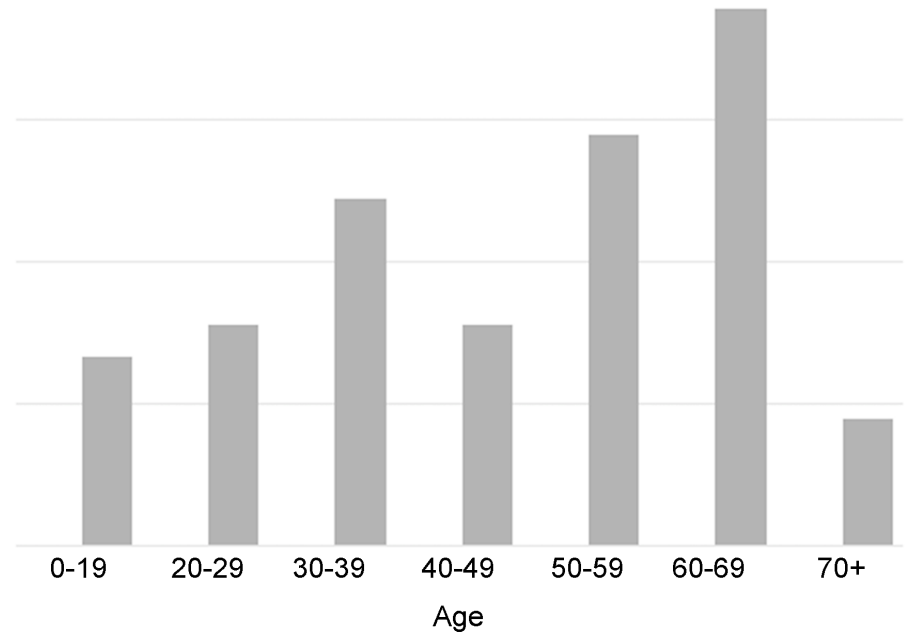

Figure 4. Age distribution of SSE.

40

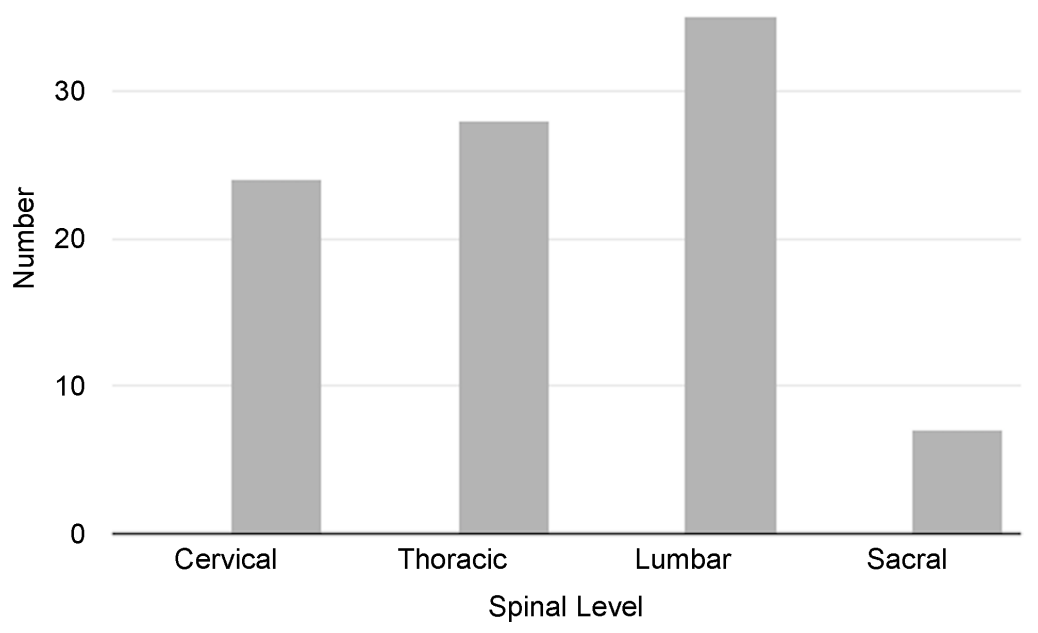

Figure 5. Infected spinal level.

30

22.5

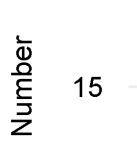

7.5

0

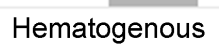

Contiguous

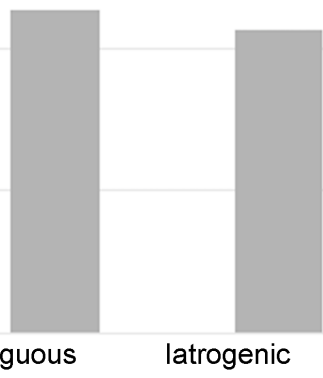

Route of Infection

Figure 6. Etiology of SSE. 


\begin{tabular}{|l|r|r|}
\hline Organism & \# & \multicolumn{1}{l|}{$\%$} \\
\hline Staphylococcus aureus (MSSA) & 33 & 49 \\
\hline Unknown & 10 & 15 \\
\hline Streptococcus species & 10 & 15 \\
\hline Sterile & 3 & 4 \\
\hline Staphylococcus aureus (MRSA) & 2 & 3 \\
\hline Other (listed below) & 10 & 15 \\
\hline & & \\
\hline Salmonella & 1 & 1.5 \\
\hline Mycoplasma hominis & 1 & 1.5 \\
\hline Pseudomonas aeruginosa & 1 & 1.5 \\
\hline Peptococcus magnus & 1 & 1.5 \\
\hline Mycobacterium tuberculosis & 1 & 1.5 \\
\hline Corynebacterium diphtheriae & 1 & 1.5 \\
\hline Escherichia coli & 1 & 1.5 \\
\hline Bacteroides fragilis & 1 & 1.5 \\
\hline Enterobacter cloacae & 1 & 1.5 \\
\hline Polymicrobial & 1 & 1.5 \\
\hline
\end{tabular}

40

30

$\stackrel{\text { है }}{\bar{z}}^{\bar{\Phi}} 20$

10

MSSA Unknown Strep Sp. Sterile MRSA Other Organism

Figure 7. Infecting organism.

\section{Surgical Outcomes}

\begin{tabular}{|l|r|r|}
\hline Recovery & \multicolumn{1}{|l|}{ \# } & \multicolumn{1}{l|}{$\%$} \\
\hline Full & 21 & 44 \\
\hline Moderate & 14 & 29 \\
\hline Minimal & 5 & 10 \\
\hline Poor & 2 & 4 \\
\hline Died & 6 & 13 \\
\hline
\end{tabular}

Non-Surgical Outcomes

\begin{tabular}{|l|r|r|}
\hline Outcomes & \multicolumn{1}{|l|}{ \# } & \multicolumn{1}{|c|}{$\%$} \\
\hline Full & 1 & 14 \\
\hline Moderate & 2 & 29 \\
\hline Minimal & 1 & 14 \\
\hline Poor & 0 & 0 \\
\hline Died & 3 & 43 \\
\hline
\end{tabular}

50

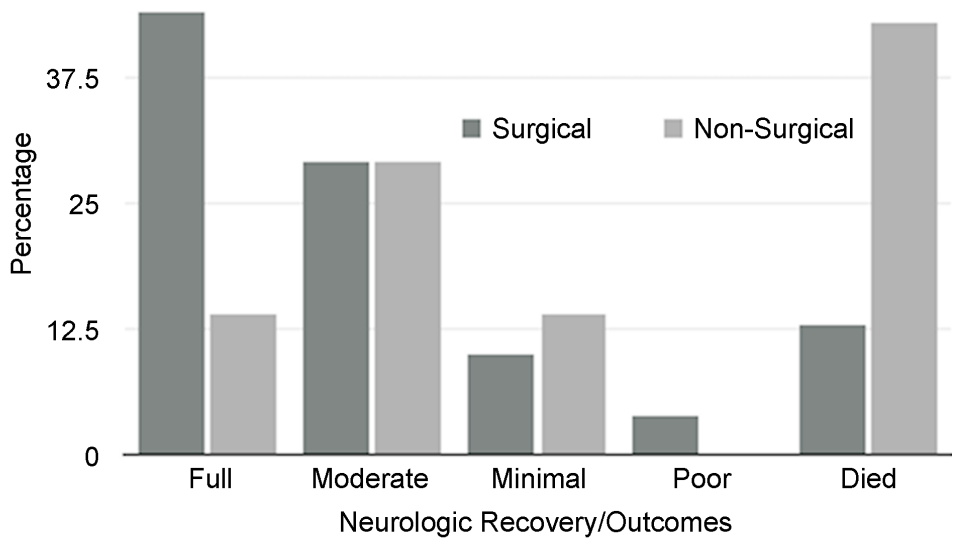

Figure 8. Surgical and non-surgical outcomes.

disturbances. $74 \%$ of reported cases were associated with neurologic deficits, often motor weakness. The more advanced stage of the natural history often consists of paralysis, incontinence, and complete sensory loss. Similar to SEA, the pathomechanism of acute motor weakness is believed due to either mechanical compression of the neural elements or septic thrombophlebitis of the venous drainage resulting in increased venous pressures and subsequent infarction of neural tissue. 
Notably, lab work is not a very sensitive indicator of SSE; only $57 \%$ of patients presented with a leukocytosis [8]. Unlike epidural abscess, spinal subdural empyema is not reliably associated with tenderness to palpation as only $23 \%$ of cases presented with that symptom [9] [10].

SSE spans a wide age distribution but $46 \%$ of cases occurred in those between ages 50 and 69 . There is a slight female predilection that is not statistically significant. The lumbar level is affected most commonly in 53\% of reported cases, followed by thoracic in $43 \%$, cervical in $37 \%$, and sacral in $11 \%$. Many cases spanned more than one spinal area. Staphylococcus aureus species is by far the most common organism [11]. It was cultured in 52\% of cases. Methicillin resistant staphylococcus aureus was only cultured in 2 cases [12]. All Streptococcus species was the next most prevalent group and was cultured in 15\% of cases. $19 \%$ of cases were reported as either sterile or unknown. $15 \%$ of cases were listed as "Other" and consist of a variety of single cases of different organisms.

Although the pathomechanism of infection is unclear, three methods of spread, hematogenous, contiguous, and iatrogenic, have been postulated in the literature [4] [6] [10] [13] [14]. Hematogenous spread, which encompasses pathologies consisting of but not limited to sepsis, pneumonia, and IV drug abuse, is the most common method of infection and occurred in $43 \%$ of cases. $28 \%$ of cases consisted of contiguous spread, which included wound infections, furuncles, sinusitis, decubitus ulcers, abscesses, cellulitis, dermoid cysts, and a spinal cord tumor [4] [15] [16] [17] [18]. 25\% of cases were iatrogenic and consisted mostly of lumbar punctures, but there were also case reports of infected blood patches for a cerebrospinal fluid leak after epidural anesthesia, discography, and a dural tear during spinal surgery [2] [6] [19] [20] [21] [22]. Multiple co-morbidities are believed to increase the risk for SSE including diabetes mellitus, alcoholism, end stage renal disease, lupus erythematosus, Crohn's disease, human immunodeficiency virus infection, and congenital anatomical abnormalities of the vertebral column or spinal cord including dermal sinus tracts [3] [4] [19] [23] [24] [25].

The current preferred diagnostic modality is gadolinium contrast enhanced MRI [3] [20] [26] [27]. The presence of dorsal epidural fat is often a distinguishing feature between epidural and subdural lesions [28]. Recommendations for empiric antibiotics include a combination of vancomycin, a cephalosporin, and metronidazole which is adjusted appropriately based on the results of cultures and sensitivities [4].

Due to the unpredictable course of the disease and frequent neurologic deficits, the recommended treatment is emergent surgical evacuation of the subdural abscess with durotomy, copious irrigation, and primary dural repair followed by parenteral antibiotics [3] [11] [14] [20]. 43\% of patients managed with antibiotics alone died and another $14 \%$ had minimal recovery. In contrast, $73 \%$ of patients managed with surgical evacuation of the empyema and parenteral antibiotics had full or marked recoveries. The mortality rate of surgically treated spinal subdural empyema is $13 \%$. Skip laminectomies along with irrigation via red 
rubber catheter is a technical option described in various cases reports with the goal of minimizing morbidity in an already ill patient and avoiding iatrogenic destabilization [28] [29]. In cases of epidural infection, the dura should be closely inspected and if unusually tense, ultrasonography or intradural exploration are intraoperative considerations to rule out an occult subdural abscess [11] [30]. Although most patients had considerable co-morbidities, factors associated with poor outcomes should be delineated in future studies to better guide treatment decision making.

The exact method of infection of the subdural space in the presented case is uncertain. The patient had a lumbar laminectomy 7 months earlier with no reported dural tear. The patient was diagnosed with pneumonia 2 weeks prior to her presentation with neurological deficits and continued confusion. Since the most common proposed method of developing subdural empyema is hematogenous spread into the subdural space, sepsis secondary to pneumonia is the suspected source.

\section{References}

[1] Harris, L.F., et al. (1987) Subdural Empyema and Epidural Abscess: Recent Experience in a Community Hospital. Southern Medical Journal, 80, 1254-1258. https://doi.org/10.1097/00007611-198710000-00014

[2] Lownie, S.P. and Ferguson, G.G. (1989) Spinal Subdural Empyema Complicating Cervical Discography. Spine (Phila Pa 1976), 14, 1415-1417. https://doi.org/10.1097/00007632-198912000-00023

[3] Velissaris, D., et al. (2009) Spinal Subdural Staphylococcus Aureus Abscess: Case Report and Review of the Literature. World Journal of Emergency Surgery, 4, 31. https://doi.org/10.1186/1749-7922-4-31

[4] Usoltseva, N., et al. (2014) Spinal Subdural Abscess: A Rare Complication of Decubitus Ulcer. Clinical Medicine \& Research, 12, 68-72.

[5] Pompucci, A., et al. (2007) Cranio-Spinal Subdural Empyema Due to $S$. intermedius. A Case Report. Journal of Neuroimaging: Official Journal of the American Society of Neuroimaging, 17, 358-360.

[6] Coumans, J.V. and Walcott, B.P. (2011) Rapidly Progressive Lumbar Subdural Empyema Following Acromial Bursal Injection. Journal of Clinical Neuroscience, 18, 1562-1563. https://doi.org/10.1016/j.jocn.2011.03.009

[7] Heusner, A.P. (1948) Nontuberculous Spinal Epidural Infections. The New England Journal of Medicine, 239, 845-854. https://doi.org/10.1056/NEJM194812022392301

[8] Lim, H.Y., et al. (2013) Chronic Spinal Subdural Abscess Mimicking an IntraduralExtramedullary Tumor. European Spine Journal, 22, 497-500. https://doi.org/10.1007/s00586-013-2700-1

[9] Fraser, R.A., et al. (1973) Spinal Subdural Empyema. Archives of Neurology, 28, 235-238. https://doi.org/10.1001/archneur.1973.00490220043005

[10] Vural, M., et al. (2005) Spinal subdural Staphylococcus aureus Abscess: Case Report and Review of the Literature. Acta Neurologica Scandinavica, 112, 343-346. https://doi.org/10.1111/j.1600-0404.2005.00496.x

[11] Bartels, R.H., Jong, D. and Grotenhuis, J.A. (1992) Spinal Subdural Abscess. Case Report. Journal of Neurosurgery, 76, 307-311. 
[12] Chern, S.H., et al. (2009) Methicillin-Resistant Staphylococcus aureus Retropharyngeal Abscess Complicated by a Cervical Spinal Subdural Empyema. Journal of Clinical Neuroscience, 16, 144-146.

[13] Heindel, C.C., Ferguson, J.P. and Kumarasamy, T. (1974) Spinal Subdural Empyema Complicating Pregnancy. Case Report. Journal of Neurosurgery, 40, 654-656. https://doi.org/10.3171/jns.1974.40.5.0654

[14] De Bonis, P., et al. (2009) Cranial and Spinal Subdural Empyema. British Journal of Neurosurgery, 23, 335-340. https://doi.org/10.1080/02688690902939902

[15] Dacey, R.G., et al. (1978) Spinal Subdural Empyema: Report of Two Cases. Neurosurgery, 3, 400-403.

[16] Harries-Jones, R., et al. (1990) Meningitis and Spinal Subdural Empyema as a Complication of Sinusitis. Journal of Neurology, Neurosurgery, and Psychiatry, 53, 441.

[17] Babu, R., et al. (1992) Intramedullary Abscess Associated with a Spinal Cord Ependymoma. Neurosurgery, 30, 121-123.

[18] Baker, R.P., Brown, E.M. and Coakham, H.B. (2003) Overwhelming Cranial and Spinal Subdural Empyema Secondary Infected Sacral Decubitus Ulcers. British Journal of Neurosurgery, 17, 572-573. https://doi.org/10.1080/02688690310001626886

[19] Chen, C.Y., et al. (1999) Dermoid Cyst with Dermal Sinus Tract Complicated with Spinal Subdural Abscess. Pediatric Neurology, 20, 157-160.

[20] Wu, A.S., et al. (2004) Spinal Subdural Empyema after a Dural Tear. Case Report. Neurosurgical Focus, 17, E10. https://doi.org/10.3171/foc.2004.17.6.10

[21] Hos, N.J., et al. (2014) Autoinfection as a Cause of Postpartum Subdural Empyema Due to Mycoplasma hominis. Infection, 43, 241-244.

[22] Kraeutler, M.J., et al. (2014) Spinal Subdural Abscess Following Epidural Steroid Injection. Journal of Neurosurgery Spine, 22, 90-93.

[23] Hershkowitz, S., et al. (1990) Spinal Empyema in Crohn's Disease. Journal of Clinical Gastroenterology, 12, 67-69. https://doi.org/10.1097/00004836-199002000-00017

[24] Alvarez Sastre, C., et al. (2002) Subdural Empyema with Extension to Vertebral Canal Secondary to Salmonellosis in a Patient with Systemic Lupus Erythematosus. Child s Nervous System, 18, 528-531. https://doi.org/10.1007/s00381-002-0618-8

[25] Alessi, G., Lemmerling, M. and Nathoo, N. (2003) Combined Spinal Subdural Tuberculous Empyema and Intramedullary Tuberculoma in an HIV-Positive Patient. European Radiology, 13, 1899-1901. https://doi.org/10.1007/s00330-002-1678-6

[26] Levy, M.L., et al. (1993) Subdural Empyema of the Cervical Spine: Clinicopathological Correlates and Magnetic Resonance Imaging. Report of Three Cases. Journal of Neurosurgery, 79, 929-935. https://doi.org/10.3171/jns.1993.79.6.0929

[27] Greenlee, J.E. (2003) Subdural Empyema. Current Treatment Options in Neurolo$g y$, 5, 13-22. https://doi.org/10.1007/s11940-003-0019-7

[28] Khalil, J.G., et al. (2013) Thoracolumbosacral Spinal Subdural Abscess: Magnetic Resonance Imaging Appearance and Limited Surgical Management. Spine, 38, E844-E847. https://doi.org/10.1097/brs.0b013e31828d5f30

[29] Sathi, S., et al. (1994) Spinal Subdural Abscess: Successful Treatment with Limited Drainage and Antibiotics in a Patient with AIDS. Surgical Neurology, 42, 424-427.

[30] Price, D.B., et al. (1993) Spinal Subdural Empyema: Appearance on Intraoperative Sonography. Journal of Ultrasound in Medicine: Official Journal of the American Institute of Ultrasound in Medicine, 12, 493-495. 
Submit or recommend next manuscript to SCIRP and we will provide best service for you:

Accepting pre-submission inquiries through Email, Facebook, LinkedIn, Twitter, etc. A wide selection of journals (inclusive of 9 subjects, more than 200 journals)

Providing 24-hour high-quality service

User-friendly online submission system

Fair and swift peer-review system

Efficient typesetting and proofreading procedure

Display of the result of downloads and visits, as well as the number of cited articles Maximum dissemination of your research work

Submit your manuscript at: http://papersubmission.scirp.org/

Or contact ojmn@scirp.org 